a recommended standard ....

\title{
AN IDENTIFICATION SYSTEM FOR OCCUPATIONALLY HAZARDOUS MATERIALS
}

U.S. DEPARTMENT OF HEALTH, EDUCATION, AND WELFARE Public Health Service Center for Disease Control National Institute for Occupational Safety and Health 


\section{a recommended standard . . . .}

\section{AN IDENTIFICATION SYSTEM FOR OCCUPATIONALLY HAZARDOUS MATERIALS}

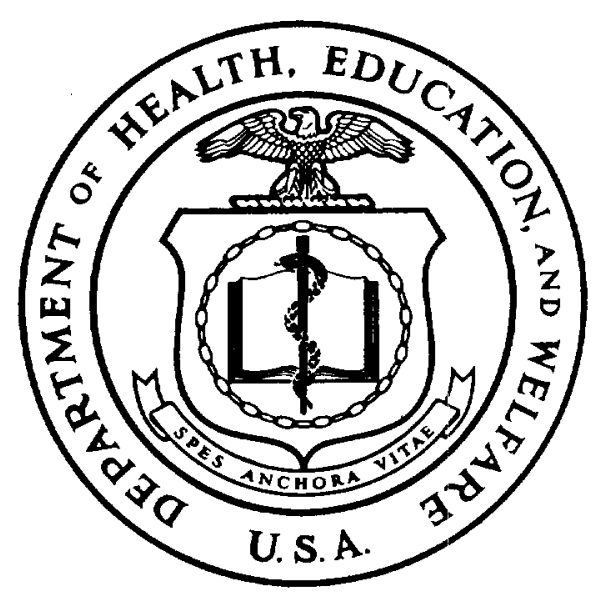

U.S. DEPARTMENT OF HEALTH, EDUCATION, AND WELFARE Public Health Sc vice

Center for Disease Control.

National Institute for Occupational Safety and Health 
PREFACE

The Occupational Safety and Health Act of 1970 emphasizes the need for Standards to protect the health and safety of workers exposed to an ever-increasing number of potential hazards at their workplace. This document, which recommends an identification system for occupationally hazardous materials, is designed to allow the rapid determination of the relative danger that may result from exposure to materials found in the workplace.

I am pleased to acknowledge the contributions to this report by the staff of NIOSH and the valuable constructive comments by the Review Consultants on identification systems, and by Robert B. O'Connor, M.D., NIOSH consultant in occupational medicine. The NIOSH recommendations are not necessarily a consensus of all of the consultants that reviewed this document. A list of the NIOSH Review Committee members and of the Review Consultants appears on pages vi and vii.




The Industrial Hygiene Services Branch, Division of Technical Services (DTS), National Institute for Occupational Safety and Health, had primary responsibility for the development of this document. The Office of Research and Standards Development (ORSD) provided coordination and review. Richard J. Lewis, Sr. of DTS had NIOSH program responsibility for the development of the document, and Frank W. Mackison of ORSD served as criteria manager. 
Robert H. Armbruster, M,D.

Palo Alto Medical Clinic

Palo Alto, California 94301

Vincent J. Castrop

Industrial Hygiene Department

General Motors Corporation

Warren, Michigan 48090

Irving H. Davis

Division of Occupational Health

Michigan Department of Health

Lansing, Michigan 48914

Hervey B. Elkins, Ph.D.

Belmont, Massachusetts 02179

Paul D. Halley

Medica1 Department

Standard Oil Company

Chicago, Illinois 60605

Robert L. Harris, Jr., Ph.D.

Raleigh, North Carolina 27609

Leonard A. Krause, Sc.D.

O1in Corporation

Branford, Connecticut 06405

Howard L. Kuznetz

Shel1 Oi1 Company

Houston, Texas 77002

James O. Pierce, Sc.D.

University of Missouri

Columbia, Missouri 65201

Carl Zenz, M.D.

Allis-Chalmers Manufacturing Company

Milwaukee, Wisconsin 53201 
A. Walter Hoover, M.D.

Division of Occupational

Health Programs

Jane A. Lee, R.N.

Division of Technical Services

Denis J. McGrath, M.D.

Office of Research and

Standards Development

Frank L. Mitche11, D.0.

office of Research and

Standards Development

Robert L. Peterson

Western Area Occupationa1

Health Laboratory

Ex Officio:

Herbert E. Christensen, D.Sc.

Office of Research and Standards

Development 


\section{A RECOMMENDED STANDARD FOR AN IDENTIFICATION SYSTEM FOR OCCUPATIONALLY HAZARDOUS MATERIALS}

Table of Contents

PREFACE

REVIEW COMMITTEES

I. RECOMMENDATIONS FOR A STANDARD: AN IDENTIFICATION SYSTEM FOR OCCUPATIONALLY HAZARDOUS MATERIALS

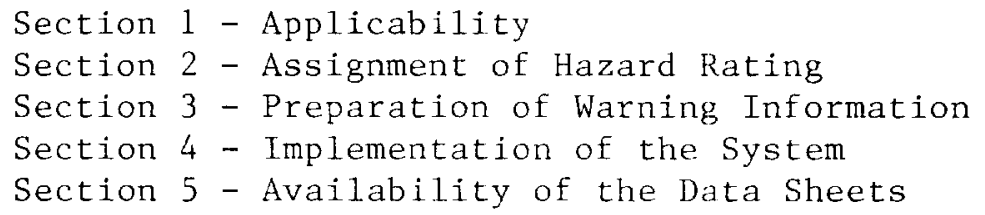

III. SCOPE AND OBJECTIVE OF THE IDENTIFICATION SYSTEM FOR OCCUPATIONALLY HAZARDOUS MATERIALS

IV. BASIS FOR THE IDENTIFICATION SYSTEM

a. Utility of the Identification System 7 for Worker Protection

b. Evaluation of Other Systems

V. COMPONENTS OF THE IDENTIFICATION SYSTEM FOR OCCUPATIONALLY HAZARDOUS MATERIALS

a. Definition of a Hazardous Material

b. Criteria for Determination of Degree of Hazard

VI. USE OF PLACARDS, LABELS, AND MSDS 43

$\begin{array}{ll}\text { VII. REFERENCES } & 47\end{array}$

IX. APPENDIX I - Glossary of Terms 50

IX. APPENDIX II - Tables of Suggested Label Statements 51 
X. APPENDIX III - Sources of Health Hazard Ratinge and Test Methods

XI. APPENDIX IV - Sources of Flammability and Reactivity Ratings 62 


\section{RECOMMENDATIONS FOR A STANDARD: AN IDENTIFICATION SYSTEM FOR OCCUPATIONALLY HAZARDOUS MATERIALS}

The National Institute for Occupational Safety and Health recommends that employees be frormed about the nature of the chemical hazards, both potential and actual, to which they may be exposed. Marking of all hazardous materials in the workplace and the availability of data sheets will help in the education of employees, and provide the data necessary for employers to take proper action to safeguard their employees.

When working in the presence of a hazardous material, hazards are always present even under work situations most carefully designed to eliminate risk. The goal of this recommendation and the intent of the Occupational Safety and Health Act of 1970 is to insure that employees can perform their duties without endangering their safety or health. This recommendation for an identification system for occupationally hazardous materials is an effort to minimize risk by alerting all concerned to the hazards inherent in chemicals found in the workplace.

A "hazardous material" is defined for the purposes of this document as a substance or mixture of substances having intrinsic properties capable of producing adverse effects on the health, or safety of the worker.

"Risk" is an assessment of the probability of adverse effects occurring in a defined set of circumstances. Risk is not a factor in the above definition of a hazardous material.

Section 1 - Applicability

An employer shall not store, distribute, make available, furnish, or supply a hazardous material for use by his employees; or make available or allow to be made available a work area containing a hazardous material as 
defined previously, unless such material or work area is labeled in accordance with Sections 2 through 5 below.

Section 2 - Assignment of Hazard Rating

A11 materials which are determined to be hazardous must be assigned a relative hazard rating in the categories of health, fire, and reactivity in accordance with the criteria contained in Chapter $V$, Section B, of this document .

Section 3 - Preparation of Warning Information

A Material Safety Data Sheet (MSDS) (Chapter V, Section C), an alert symbol (Chapter V, Section D), and labeling statements (Chapter V, Section E) shall be prepared in accordance with instructions in Chapter $V$ utilizing relative rating information regarding the hazards of the material.

Section 4 - Implementation of the System

Placards and/or labels shall be applied according to the instructions in Chapter VI. The key words shall be printed in English and in the predominant language of non-English-reading workers, unless they are otherwise trained and informed of the hazards. All illiterate workers shall receive such training.

Placards shall be posted at the entrance and within all areas containing hazardous materials in storage or use. Labels shall be applied, affixed, or attached to all containers holding hazardous materials in such a manner and in sufficient number as to be visible to and readable by all potentially exposed workers.

For substances or products containing substances listed in 29 CFR 1910.93, placards on the interior of buildings and labels shall contain the following statement: 
"This product (area) contains (list substances in the product which appear in 29 CFR 1910.93) or compounds thereof. According to regulations promulgated under the Occupational Safety and Health Act of 1970, employers using this product must make available to their employees the information required by OSHA regulations."

Placarding or extensive labeling is not required for materials of minimum hazard, ie, those with no relative hazard rating above one (1). For areas containing numerous hazardous materials, only one placard is required. This should reflect the highest hazards of each category contained in the area. Each hazardous material container, however, must bear a label specific to the material within.

Section 5 - Availability of the Data Sheets

A Material Safety Data Sheet (MSDS) sha11 be filed in the establishment where the corresponding material is in storage or use, in such a location that it sha11 be readily available for examination by workers. This location is to be made known to the employees to: (a) allow workers to ascertain the hazardous properties; (b) enable management to be informed of appropriate methods of control, worker protection, and disposal; and (c) give first aid and medical personnel rapid access to medical information during emergencies.

The current MSDS shall be made available to the representatives of the Secretary of Health, Education, and Welfare, to the Secretary of Labor, and to potentially exposed employees. 


\section{INTRODUCTION}

This report presents the recommended standard which was developed and prepared by the National Institute for Occupational Safety and Health (NIOSH) to assist in meeting the need to provide adequate information for the safety and health of employees exposed to hazardous materials. The necessary relevant information is made available in accordance with Section 22(c)(1) of the Occupational Safety and Health Act of 1970 which authorizes NIOSH to develop and establish recommended occupational safety and health standards.

Labeling is an important component of a program to ensure a safe and healthful workplace. Since labeling by itself is insufficient, other methods of informing and educating the worker must also be used.

This recommended standard describes a system designed to inform the worker of the presence and nature of, and appropriate response to, such hazardous materials as may be encountered in the workplace. 


\section{SCOPE AND OBJECTIVE OF THE IDENTIFICATION SYSTEM}

FOR OCCUPATIONALLY HAZARDOUS MATERIALS

The intent of the Occupational Safety and Health Act of 1970 is to provide a safe and healthful working place for all employees covered by the Act. Section 6(b)(7) of the Act states "Any standard promulgated under this subsection shall prescribe the use of labels or other appropriate forms of warning as are necessary to insure that employees are apprised of all hazards to which they are exposed, relevant symptoms and appropriate emergency treatment, and proper conditions and precautions of safe use or exposure."

The broad objectives of any adequate hazardous warning system for worker protection are:

(a) To provide immediate warning of potential danger so that injury, i1lness, or death may be prevented.

(b) To describe the nature of the hazard.

(c) To indicate actions to be taken to prevent undue or accidental exposure under conditions of normal use or during emergencies.

(d) To give instructions to minimize injurious effects in the event of exposure.

Labels, placards, and similar warning devices have been used to warn of potentially hazardous conditions. However, there has never been a uniform and complete system to identify materials found in the workplace. The recommended standard responds to that portion of the Act quoted above. It is designed to inform the employee of potentially hazardous materials as 
they are encountered in the workplace by a three-component warning system based on the use of placards, labels, and Material Safety Data Sheets.

These components collectively:

Identify the hazardous materials

Indicate the degree and type of hazard(s)

Describe signs and symptoms from overexposure

Prescribe safe handling procedures

Describe the proper emergency care in the event of overexposure

Indicate disposal methods 
IV. BASIS FOR THE IDENTIFICATION SYSTEM

A single comprehensive labeling system applicable to every hazardous material under all circumstances is a desirable goal. All those affected would come to understand a universal system and recognize hazard potential whether the material was encountered in the home, in the workplace, or in transport. The elimination of confusion from multiple labeling systems and economy of application would be real benefits of a universal system, but was beyond the scope of NIOSH's mandate.

In responding to the need for worker protection, NIOSH first sought to adapt existing systems for use in the workplace. As work progressed, numerous modifications and additions forced the realization that adaption of a single system would not suffice to protect the health of the worker. The identification system presented in this document is specifically tailored for use in the workplace to provide warning and information concerning hazardous materials encountered in the workplace.

(a) Utility of the Identification System for Worker Protection

The Identification System possesses the following characteristics, al1 of which are considered to be essential to the success of an employee safety and health hazard warning system: (1) The Identification System is comprehensive in that it addresses itself to both safety and health considerations. In the past, labels and placards have stressed job safety with less attention being paid to safeguarding the health of workers from hazardous materials encountered in the workplace. It is essential that delayed or chronic health effects must be given the same attention as are 
immediate or acute problems. Thus, it is essential that any information system contain a health hazard component. (2) The warning labels and placards describe levels for potential harm. The employee is able to determine in the work environment, by observation and comprehension of the precautionary labels and placards, the relative injury and illness hazards inherent in the material which may be encountered. (3) The Identification System provides for the furnishing of detailed information on the hazard. The Material Safety Data Sheet contains additional chemical, physical, and medical data to allow adequate preplanning of controls and optimum response to excessive exposure.

\section{(b) Evaluation of Other Systems}

Several other systems are currently in use to identify, instruct, or warn individuals about potential or actual hazards which may endanger their safety and health. These systems vary greatly in scope, degree of information imparted, visual appearance, and intended uses. Several aspects of existing systems are applicable to the work environment and have been adapted for use in the recommended standard.

The Food and Drug Administration (FDA) has requirements for the labeling of foods and drugs implemented under the provisions of the Federal Food, Drug, and Cosmetic Act. 52 Stat. 1040(1938), 21 USC Sec. 301(1970). They are intended to protect the consumer from misbranded, unwholesome, ineffective, and hazardous products. FDA labeling requirements are consumer-; not worker-; oriented.

The Consumer Product Safety Commission (CPSC) has responsibility for labeling hazardous materials when they appear in consumer goods. The 
definitions of hazard as found in the Hazardous Substances Act as amended and the Poison Prevention Packaging Act of 1970 are consumer- and especially child-oriented. The wording of the required warnings are similar to those of the Manufacturing Chemists Association (MCA) [1]

The Enviromental Protection Agency (EPA) requires that economic poisons, such as chemical pesticides, sold to the public contain labels that carry health hazard warnings. The basic regulations are given in the Federal Insecticide, Fungicide, and Rodenticide Act. 61 Stat. 163(1947), USC Sec. 121(1970). These labels consist of warning statements without a numerical hazard rating. They are for user protection.

The United Nations (UN) [2] has developed a pictorial system indicating major hazards such as flammability, toxicity, and explosivity. The pictographs give no indication of the degree of hazard and are more suitable for inclusion as part of a more complex system.

The US Department of Transportation (DOT) published a notice in the Federa1 Register, Volume 39, pages 3022-3241, January 24, 1974, of its intent to promulgate a Hazard Information (HI) system. It is intended to provide a comprehensive and effective method of communication to aid in the protection of the public as well as fire law enforcement, and other emergency response personnel, when transportation incidents involving hazardous materials occur. The proposed HI system is designed to enable fire and police personnel arriving at scenes of hazardous materials transportation emergencies to quickly determine necessary precautions and appropriate actions. This system is not intended to protect the safety and health of employees in general from potentially hazardous materials and conditions present in the workplace. The HI system consists of a diamond 
shaped placard containing a UN pictorial in the upper portion, a hazard term in the center, and a two-digit number in the lower half. The number refers to a corresponding data card which contains detailed emergency response data for the hazard class denoted by the two-digit number, where the first digit identifies the hazard class.

The HI system does not assign graduated relative equivalent levels of risk. The HI two-digit number refers the observer to an appropriate response card which contains generic hazard information. Thus, the placard tells the worker the general category of the material involved provided the hazard classifications have been committed to memory, or the HI cards are readily accessible.

In addition, it does not always convey the warning of all hazards. The second digit bears no uniform relationship to the nature of risk of additional hazards. Reference must be made to the appropriate card.

Based on the foregoing discussion, the HI system does not warn the worker of all safety and health hazards to which he may be exposed and therefore does not meet the basic criteria for an adequate warning system for workers.

The National Fire Protection Association (NFPA) has developed the "Recommended System for the Identification of the Fire Hazards of Materials." [3] This system, like the DOT HI system, has numerical ratings but lacks any detailed format for data on specific hazardous materials. It is intended primarily to provide protection for emergency response personnel, particularly firemen, and is limited in scope. It identifies the hazards of chemical materials in terms of three principal categories, ie, health, flammability, and reactivity (instability); and the 
order of severity numerically by five divisions ranging from four (4), indicating a severe hazard, to zero (0), indicating no special hazard.

However, the health hazard rating is based on the concept that a fire fighter will normally receive "a single exposure which may vary from a few seconds up to an hour." [3] In contrast, employees routinely working with hazardous materials can be exposed for the duration of their working lives. In addition, the NFPA system recognizes two sources of health hazards, one rising out of the inherent properties of the substance, the other resulting from either combustion or decomposition of the material. The effects of combustion and/or decomposition of a substance are not relevant when assigning a health hazard rating to materials where workers are not exposed to combustion products. The NFPA system stresses that "the hazard degree should be assigned on the basis of the greater hazard that could exist under fire or other emergency conditions." [3] Therefore, a different health hazard rating may be assigned to a hazardous material than is warranted to warn the worker under nonemergency conditions. Thus, the NFPA system may not impart a valid health hazard warning to employees whose jobs are to work with the substance under normal circumstances, ie, in the absence of fire or other emergency. The concept of assigning relative ratings to denote relative risk is a useful one and is used in this NIOSH recommended standard.

Another widely used precautionary labeling system is the "Labels and Precautionary Information (LAPI)" [1] system of the Manufacturing Chemists Association (MCA). The LAPI system recommends the use of precautionary labels bearing such information as the product name; signal words designating the degree of hazard (eg, Danger, Warning, or Caution); 
affirmative statement of hazards; precautionary measures covering actions to be followed or avoided; instructions in case of contact or exposure; antidotes and notes to physicians; instructions in case of fire, spill, or leak; and instructions for container handing and storage. MCA Chemica1 Safety Data Sheets and other forms of information are available to support the precautionary labels for some substances. The system does not provide for the preparation of data sheets for products or a numerical rating system. The LAPI system contains effective worker-oriented statements, many of which are used in a modified form in the NIOSH recommended standard.

Based on the foregoing evaluation, the recommended standard of the National Institute for Occupational Safety and Health draws upon the most effective features of each system. It presents a placard/label/data sheet format designed to inform workers of all potential hazards which may confront them when working with a hazardous material. 